\title{
Endosialin (CD248) Expression in Fibromas and Soft-tissue Fibrosarcomas in Dogs
}

\author{
MAGDALENA MARZEC, MAŁGORZATA KANDEFER-GOLA, \\ IZABELA JANUS, JOANNA BUBAK and MARCIN NOWAK \\ Department of Pathology, Division of Pathomorphology and Forensic Veterinary Medicine, \\ Wroclaw University of Environmental and Life Sciences, Wroclaw, Poland
}

\begin{abstract}
Background/Aim: Endosialin is present in human fibrosarcoma neoplastic cells. This study aimed to analyse the expression of selected cellular proteins found in fibrosarcomas and soft-tissue fibroids in dogs. Materials and Methods: A total of 71 skin tumours obtained from dogs were used. The samples included 31 fibromas and 40 fibrosarcomas. Histopathological evaluation was performed according to World Health Organization guidelines. Immunohistochemistry was performed with anti-endosialin, Ki-67, cyclo-oxygenase 2 and vimentin antibodies and assessed using the semiquantitative scale. Results: Endosialin expression was observed in $82.5 \%$ of fibrosarcomas and in $35 \%$ of fibromas. A significant positive correlation was found between the expression of endosialin in fibrosarcoma neoplastic cells and the degree of histological malignancy and the expression of the Ki-67 and cyclo-oxygenase 2 antigen. Expression of vimentin confirmed the mesenchymal origin of these tumours. Conclusion: The results of our research suggest that endosialin is involved in the carcinogenesis of fibrosarcoma in dogs.
\end{abstract}

Fibrosarcomas are neoplasms originating from fibrous tissue, myofibroblasts and fibroblasts, including immature proliferating fibroblasts (1). We include them in the group of soft-tissue sarcomas (STS). STSs are invasive neoplasms whose metastatic potential is directly proportional to the grade of malignancy (2). In dogs, among skin and subcutaneous tissue cancer types, STS constitutes $6 \%$ of all

This article is freely accessible online.

Correspondence to: Magdalena Marzec, Department of Pathology, Division of Pathomorphology and Forensic Veterinary Medicine, Wroclaw University of Environmental and Life Sciences, Wroclaw, Poland. Tel: +48 713205444, e-mail: Magdalena.marzec@upwr.edu.pl

Key Words: Endosialin (CD248), fibrosarcoma, fibroma, dog. proliferative lesions $(3,4)$. Contrary to humans, in animals, mesenchymal neoplasms are more common than epithelial tumours, except for changes in the skin and the mammary gland, a phenomenon that has not been explained so far (5).

Unfortunately, in the early stages of development, such a tumour is relatively small and not painful, and therefore often goes unnoticed by pet owners. Later in the growth stage, fibrosarcomas become large and tend to infiltrate the surrounding tissues and metastasize (6).

In veterinary medicine, immunohistochemical tests (IHC) are being used more and more often in histopathological diagnostics, they allow for a precise assessment of neoplastic lesions, especially those with poor differentiation. Assessment of the level of expression of cellular markers in IHC studies also allows for a more accurate determination of the patient's prognosis and targeting of therapeutic management.

Endosialin (CD248) was first described in 1992 as an antigen produced by murine cells immunised with human foetal fibroblasts (7). Subsequent studies showed that the antibody to endosialin reacted with neoplastic cells in sarcomas, while no reaction was found in normal tissues (8). The presence of endosialin in fibroblasts and pericytes of the human thymus, spleen and lymph nodes has also been confirmed, and its expression appears to be intense during the development of lymphoid tissue; in adults, it is usually absent, except for the endometrium, corpus luteum and marrow fibroblasts $(9,10)$.

This study aimed to analyse the expression of selected cellular proteins found in fibrosarcomas and soft-tissue fibroids in dogs. We used antibodies against the proteins endosialin, Ki-67, cyclo-oxygenase 2 (COX2) and vimentin. Another aim was to determine the correlation between the tumour grade and the level of expression of the abovementioned proteins. Vimentin was used to confirm the mesenchymal origin of the tumours. The level of endosialin expression was compared with the expression of already known proteins correlating with tumour grade, namely $\mathrm{Ki}$ 67 and COX2. To our knowledge, the presence of endosialin 
in vivo $35: 1467-1472(2021)$

Table I. Expression of the studied proteins in fibroma ( $n=31)$ and fibrosarcoma (FS) $(n=40)$. The table shows the cases divided into groups according to the intensity of immunoreaction. Data are presented as a percentage of all cases (\%). Expression values were found to be significantly higher in fibrosarcoma than in fibroma for endosialin $(p<0.001)$, Ki-67 $(p=0.005)$ and cyclo-oxygenase $2(C 0 X 2)(p=0.02)$.

\begin{tabular}{|c|c|c|c|c|c|c|c|c|}
\hline \multirow{2}{*}{$\begin{array}{l}\text { Reaction } \\
\text { intensity }\end{array}$} & \multicolumn{2}{|c|}{ Vimentin } & \multicolumn{2}{|c|}{$\mathrm{COX} 2$} & \multicolumn{2}{|c|}{ Endosialin } & \multicolumn{2}{|c|}{ Ki-67 } \\
\hline & Fibroma & FS & Fibroma & FS & Fibroma & FS & Fibroma & FS \\
\hline - & 0 & 0 & 100 & 82.5 & 65 & 17.5 & 84 & 50 \\
\hline+ & 0 & 5 & 0 & 2.5 & 16 & 17.5 & 13 & 27.5 \\
\hline++ & 19 & 22.5 & 0 & 15 & 19 & 17.5 & 3 & 15 \\
\hline+++ & 81 & 72.5 & 0 & 0 & 0 & 47.5 & 0 & 7.5 \\
\hline
\end{tabular}

has not yet been confirmed in fibromas or fibrosarcomas of the skin and subcutaneous tissue in dogs.

\section{Materials and Methods}

This research was carried out on 71 tumours of the skin and subcutaneous tissue of $\operatorname{dog} s$, of various breeds and sexes (aged 4 to 15 years) previously classified as fibroids (fibromas, 31 tumours) and fibrosarcomas (40 tumours). The material tested came from the archives of the Department of Pathomorphology and Forensic Veterinary Medicine of the University of Life Sciences in Wrocław from 2019-2020.

The collected tumour sections were fixed in $7 \%$ formalin solution for $24 \mathrm{~h}$, then embedded in paraffin blocks and cut into 4 $\mu \mathrm{m}$-thick sections. The obtained preparations were stained with haematoxylin and eosin, and then histopathological evaluation was performed according to World Health Organization guidelines (11). The evaluation took into account three parameters determined on a 3-point scale: i) Histological differentiation of tumour cells, scoring 1 for well-differentiated cells, 2 for poorly differentiated and 3 for poorly differentiated; ii) number of mitoses seen in 10 fields of view at high-power magnification $(\times 400)$, scoring 1 for 0 9 mitotic divisions/HPF, 2 for 10-19 mitotic divisions/HPF, 3 for $>19$ mitotic divisions/HPF; iii) area of necrosis, scoring 0 for no tumour necrosis, 1 for $\leq 50 \%$ necrosis, and 2 for $>50 \%$ area of necrosis. From the sum of the points, three grades of malignancy were distinguished: Grade 1: 2-3 points; 2 : 4-5 points; and 3: 6-8 points (12).

IHC studies were performed on 4- $\mu$ m-thick paraffin sections that were placed on glass slides (Menzel-Glaser ${ }^{\circledR}$ ), then the sections were dewaxed in xylene and run through an alcohol series of decreasing concentration to water. Formalin-fixed tissue antigens were discovered in EnVision ${ }^{\mathrm{TM}}$ FLEX Target Retrieval Solution, High pH $\left(\right.$ Dako $\left.^{\circledR}\right)$ for COX2, and Ki-67, endosialin and vimentin in EnVision $^{\mathrm{TM}}$ FLEX Target Retrieval Solution, Low pH (Dako $\left.{ }^{\circledR}\right)$. All slides were heated in a water bath at $96^{\circ} \mathrm{C}$ for 20 minutes. Endogenous peroxidase was blocked in EnVision $^{\mathrm{TM}}$ FLEX Peroxidase-Blocking Reagent for 10 minutes. Primary antibodies from Dako ${ }^{\circledR}$ against vimentin (mouse monoclonal, clone V9; dilution 1: 100), COX2 (mouse monoclonal, CX-294; dilution 1:100), Ki-67 (monoclonal mouse MIB-1; dilution 1:100), and Novus Biologicals endnosialin (rabbit polyclonal; dilution 1:400) were applied to the sections. All were incubated for 20 minutes at room temperature. Subsequent steps were rinsing in EnVision ${ }^{\mathrm{TM}}$ FLEX WashBuffer and spotting EnVision ${ }^{\mathrm{TM}}$ FLEX/HR SM802 reagents onto the sections, incubating for 20 minutes at room temperature. The IHC reaction was visualised using a solution of 3,3'-diaminobenzidine tetrahydrochloride (DAB), EnVision ${ }^{\mathrm{TM}}$ FLEX DAB+Chromoge $\left(\right.$ Dako $\left.^{\circledR}\right)$. The sections were then washed in distilled water, the nuclei were stained with haematoxylin and dehydrated in an alcohol series.

Photographs of the examined tumours were subjected to computer-aided image analysis using a computer coupled to an Olympus BX53 optical microscope (Olympus, Tokyo, Japan) equipped with an Olympus ColorViewIIIa digital camera (Olympus). Measurements were made using the cell^ ${ }^{A}$ and $C e l{ }^{\wedge} \mathrm{B}$ software (Olympus Soft Imaging Solution GmbH, Germany).

The level of COX2 and endosialin expression was assessed using the modified semi-quantitative scale according to Remmele and Stegner (13). The method takes into account both the percentage of positively stained cells and the colour intensity of the reaction, and its final results represent the product of both parameters with values from 0 to 12 points: no reaction $=0$ points, -; weak reaction=1-2 points, + ; moderate reaction=3-5 points, ++ ; intense reaction=6-12 points, +++. Ki-67 expression was quantified by determining the percentage of cells showing a positive nuclear response: $0-5 \%=$ no response $-; 6-25 \%=$ weak response, $+; 26-$ $50 \%=$ moderate response, ++ ; above $50 \%=$ intense reaction, +++ . The expression of the tested markers was assessed by three experienced pathologists.

Expression of vimentin in the studied material (both in fibromas and fibrosarcomas) was employed to confirm the mesenchymal origin of these tumours $(4,14)$.

Statistical analysis was performed using StatisticaPL 12.0 software (StatSoft, Kraków, Poland) and appropriate statistical tests. The normality of the data was checked using the Shapiro-Wilk test. The dependence of the obtained results was assessed based on the Spearman correlation analysis. The difference between sexes in the obtained results was assessed using the Mann-Whitney $U$-test. The significance level adopted was $p<0.05$.

\section{Results}

Fibroma samples came from 31 dogs (20 males and 11 females) aged from 4 to 12 years (median=9 years). A total of $32 \%$ of the fibromas were from mixed breeds, $13 \%$ from Labrador retrievers and isolated cases amongst the remaining breeds. Fibrosarcoma samples came from 40 dogs (22 males and 18 females) aged from 5 to 15 years (median=10 years), 
Table II. Comparison of endosialin expression in fibrosarcomas by tumour grade $(p<0.05, r=0.71)$. Endosialin expression was significantly lower in grade 1 compared to grade $2(p=0.001)$ and grade $3(p<0.001)$.

\begin{tabular}{lcccc}
\hline & \multicolumn{4}{c}{ Endosialin expression, n (\%) } \\
\cline { 2 - 5 } $\begin{array}{l}\text { Grade of } \\
\text { malignancy }\end{array}$ & - & + & ++ & +++ \\
\hline 1 & & & & \\
2 & $6(15 \%)$ & $6(15 \%)$ & $3(7.5 \%)$ & $2(5 \%)$ \\
3 & $1(2.5 \%)$ & $1(2.5 \%)$ & $4(10 \%)$ & $11(27.5 \%)$ \\
& $0(0 \%)$ & $0(0 \%)$ & $0(0 \%)$ & $6(15 \%)$ \\
\hline
\end{tabular}

mixed breeds constituting 39\%, Bernese Mountain dogs 9\%, Labrador retrievers $7 \%$, with isolated cases amongst the remaining breeds. Tumours were classified according to the grade of malignancy, where $42.5 \%$ were grade $1,42.5 \%$ grade 2 and $15 \%$ grade 3.

The results of IHC tests are presented in Tables I, II, III, IV and in Figure 1. Expression values were found to be significantly higher in fibrosarcoma than in fibroma for endosialin $(p<0.001)$, Ki-67 $(p=0.005)$ and COX2 $(p=0.02)$ Statistical analysis of the studied fibrosarcomas showed no significant difference in tumour grade according to sex or age $(p>0.05)$.

For the examined fibrosarcomas, a positive correlation (Spearman's correlation analysis) was found between: Age and COX2 expression $(p<0.05, \mathrm{r}=0.41)$, grade of malignancy and endosialin expression $(p<0.05, \mathrm{r}=0.71)$, grade of malignancy and Ki-67 expression $(p<0.05, \mathrm{r}=0.62)$, and endosialin and $\mathrm{Ki}-67$ expression $(p<0.05, \mathrm{r}=0.63), \mathrm{Ki}-67$ and COX2 expression $(p<0.05, \mathrm{r}=0.31)$.

Moreover, differences in expression of endosialin $(p<0.001)$ and Ki-67 $(p<0.001)$ depending on the tumour grade were found: Endosialin expression was significantly lower in grade 1 compared to grade $2(p=0.001)$ and grade 3 ( $p<0.001) ; \mathrm{Ki}-67$ expression was lower in grade 1 compared to grade $3(p<0.001)$, and in grade 2 compared to grade $3(p=0.01)$.

\section{Discussion}

Research on cancer biology very often focuses on finding new proteins involved in the progression of cancer. This type of research helps to better understand the mechanisms governing carcinogenesis, and at a later stage is used for IHC diagnostics and targeted therapy. Analyses carried out on animal material are very often helpful and used to understand the biological processes occurring in human tissues (15). Although in human medicine, STSs constitute only about $1 \%$ of all neoplastic lesions, they still pose many diagnostic and therapeutic difficulties (16).
Table III. Comparison of cyclo-oxygenase 2 (COX2) expression in fibrosarcomas by tumour grade.

\begin{tabular}{lcccc}
\hline & \multicolumn{4}{c}{ COX2 expression, n (\%) } \\
\cline { 2 - 5 } $\begin{array}{l}\text { Grade of } \\
\text { malignancy }\end{array}$ & - & + & ++ & +++ \\
\hline 1 & & & & \\
2 & $15(37.5 \%)$ & $0(0 \%)$ & $2(5 \%)$ & $0(0 \%)$ \\
3 & $15(37.5 \%)$ & $0(0 \%)$ & $2(5 \%)$ & $0(0 \%)$ \\
& $3(7.5 \%)$ & $1(2.5 \%)$ & $2(5 \%)$ & $0(0 \%)$ \\
\hline
\end{tabular}

Table IV. Comparison of Ki-67 expression in fibrosarcomas by tumour grade $(p<0.05, r=0.62)$. Ki-67 expression was lower in grade 1 compared to grade $3(p<0.001)$, and in grade 2 compared to grade 3 $(p=0.01)$.

\begin{tabular}{lcccc}
\hline & \multicolumn{4}{c}{ Ki-67 expression, n (\%) } \\
\cline { 2 - 5 } $\begin{array}{l}\text { Grade of } \\
\text { malignancy }\end{array}$ & - & + & ++ & +++ \\
\hline 1 & & & & \\
2 & $13(32.5 \%)$ & $3(7.5 \%)$ & $1(2.5 \%)$ & $0(0 \%)$ \\
3 & $7(17.5 \%)$ & $8(20 \%)$ & $2(5 \%)$ & $0(0 \%)$ \\
\hline
\end{tabular}

Previous studies on tumours from dogs have not shown any correlation between the frequency of skin and subcutaneous fibrosarcomas and the age, breed or sex of the animal (17). In our study, no such relationship was found either.

$\mathrm{Ki}-67$ is a protein whose expression is conventionally used as a marker of proliferation (18). This protein is present during the active phases of the cell cycle $\left(\mathrm{G}_{1}, \mathrm{~S}, \mathrm{G}_{2}, \mathrm{M}\right)$ but not expressed during the resting phase $\left(\mathrm{G}_{0}\right)$ (19). Nuclear expression of $\mathrm{Ki}-67$ has been noted in both fibroma and fibrosarcoma. Of the fibromas we examined, $84 \%$ did not express Ki-67, which confirms that the cells of these tumours do not divide as intensively as in the case of malignant tumours. Ki-67 expression in the fibrosarcomas we studied was shown in $50 \%$ of cases. Our statistical analysis showed a positive correlation between the grade of malignancy and the expression of $\mathrm{Ki}-67 \quad(p<0.05, \mathrm{r}=0.74)$. A similar relationship between the expression of $\mathrm{Ki}-67$ and the degree of histological malignancy of STS in their study was obtained by Ettinger et al. (20). The results obtained by us are similar to those shown by Nowak et al., in whose research $44 \%$ of fibrosarcoma type tumours reacted with $\mathrm{Ki}$ 67 antibody (21).

COX2 is a protein whose presence has been detected in neoplastic lesions. It is associated with neoplastic transformation of cells in neoplasms of both epithelial and 

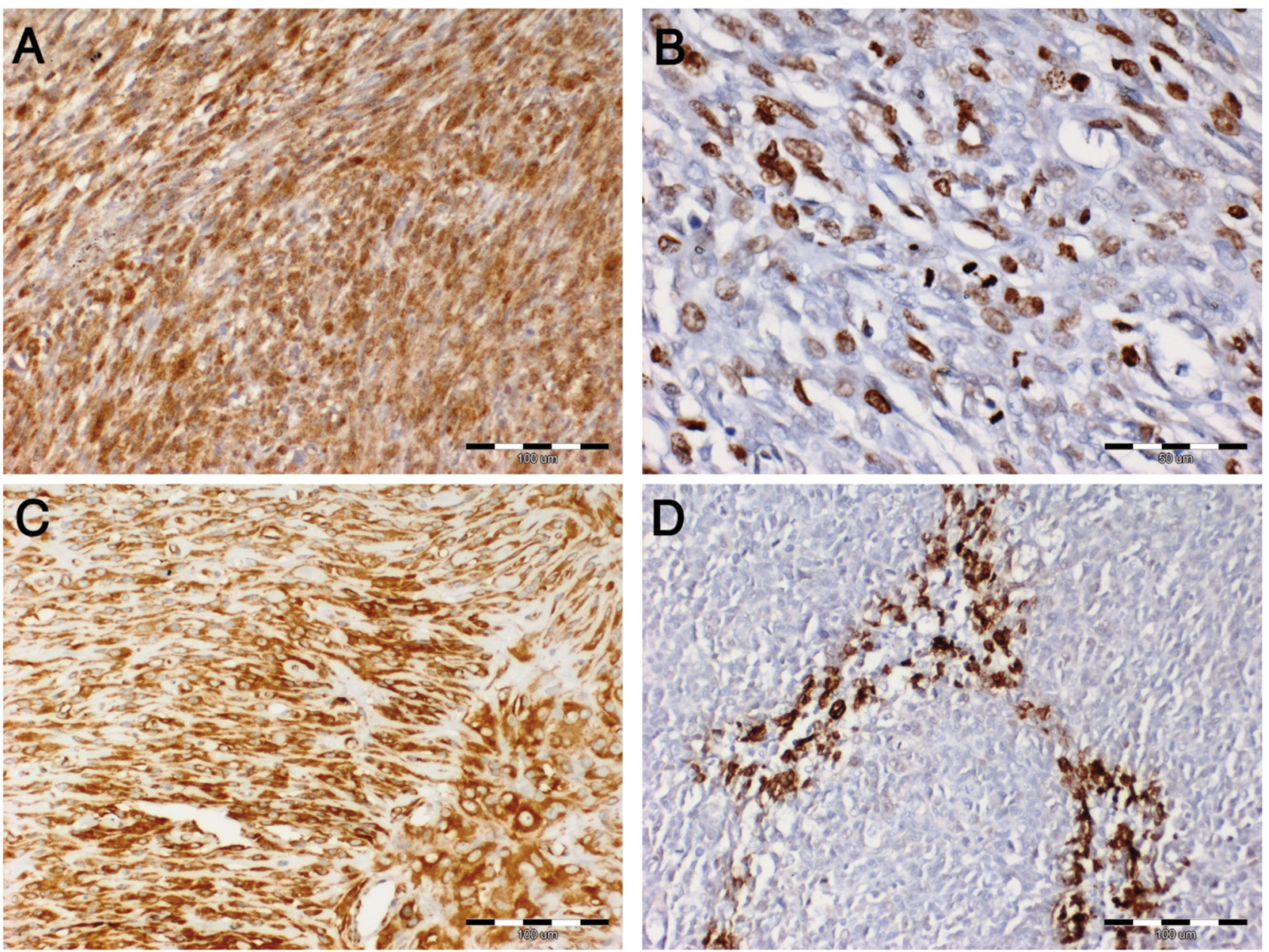

Figure 1. Immunohistochemical analysis of examined tumours, Scale bar=100 $\mu \mathrm{m}$ : A: Expression of endosialin (CD248) in the cytoplasm of fibrosarcoma cells - intense reaction. B: Expression of Ki-67 in the nucleus of fibrosarcoma cells - moderate reaction. C: Expression of vimentin in the cytoplasm of fibrosarcoma cells - intense reaction. D: Expression of cyclo-oxygenase 2 in the cytoplasm in fibrosarcoma cells - intense reaction.

mesenchymal origin. It is assumed that COX2 expression is related to the cell's ability to inhibit the process of apoptosis (22). Moreover, overexpression of COX2 in tumour cells leads to the production of high levels of prostaglandins by the body, mainly prostaglandin $\mathrm{E}_{2}$ (23). Research shows that an elevated concentration of prostaglandin $\mathrm{E}_{2}$ in the blood increases the resistance of cancer cells to apoptosis, enhances angiogenesis, increases cancer cell proliferation and induces immunosuppression $(24,25)$. In our study, COX2 expression increased with the degree of malignancy of fibrosarcoma and this was confirmed by the positive correlation shown in the statistical analysis. In the case of fibroma, COX2 expression was not detected at all. In contrast, Mohammed et al. in their studies did not confirm the presence of COX2 in STS in dogs (25). On the other hand, Nowak et al. showed a clear increase in the expression of COX2 in fibrosarcoma in dogs with the degree of malignancy (22).
Endosialin is also known an endothelial tumour marker (10). In humans, the presence of endosialin has been demonstrated in malignant tumours of mesenchymal origin, of the sarcoma type. Expression of this protein has been demonstrated in both primary tumours and metastases. Its intensity increases with the degree of histological malignancy of the tumour $(26,27)$. Moreover, high endosialin expression was positively correlated with the occurrence of metastases (28). This means that its presence in neoplastic cells may affect their metastatic potential, but the mechanisms of this action are not yet known. The presence of endosialin in foetal tissues and tumours suggests that endosialin is responsible for increased cell proliferative capacity. Our research confirmed the presence of endosialin in both fibroma, where $35 \%$ had a positive reaction, and fibrosarcoma, where $82.5 \%$ of tumours had a positive reaction. Statistical analysis showed endosialin expression to be higher in fibrosarcoma than in fibroma. 
Moreover, our research confirms a clear relationship between the increase in the intensity of the endosialin reaction and an increase in the histological degree of tumour malignancy, which is confirmed by positive correlation in statistical analysis. These results are consistent with studies conducted in humans by Thway et al. (27), As well as O'Shannessy et al. (26). Additionally, a positive correlation was demonstrated between the expression of Ki-67 and that of endosialin, which corroborates the increasing expression of endosialin in tumours with increasing cell proliferation.

We obtained a positive correlation of the expression of endosialin with Ki-67 as well as endosialin and COX2. This means that endosialin may be related to the proliferative potential of tumour cells and may be involved in tumour progression. Similar results obtained in studies on human tumours suggest that endosialin may play a similar role in dogs. The results of our research suggest that endosialin is involved in the process of carcinogenesis in fibrosarcoma in dogs.

\section{Ethical Approval}

According to the Polish law, standard diagnostic procedures and studies conducted on animal tissue and archival material do not require permission from the Ethical Board.

\section{Conflicts of Interest}

The Authors declare that they have no competing interests in regard to this study.

\section{Authors' Contributions}

Designed the study and conducted the experiments were accomplish by MM, MKG, MN. IHC and IHC evaluation were performed by MM, MKG, MN. The statistical analysis was performed by IJ. Writing and editing the paper-MM, MKG, IJ, JB, MN. All the authors have approved the final manuscript.

\section{Acknowledgements}

The Authors would like to express their appreciation of the staff of the Department of Pathology at Wroclaw University of Environmental and Life Sciences.

\section{References}

1 Schneider G, Schmidt-Supprian M, Rad R and Saur D: Tissuespecific tumorigenesis: context matters. Nat Rev Cancer 17(4): 239-253, 2017. PMID: 28256574. DOI: 10.1038/nrc.2017.5

2 Livaccari AM, Selmic LE, Reagan JK, Driskell EA, Cray MT, Lamoureux LM and Garrett LD: Evaluation of information presented within soft tissue sarcoma histopathology reports in the United States: 2012-2015. Vet Comp Oncol 16(4): 424-430, 2018. PMID: 29575744. DOI: 10.1111/vco.12397
3 Liptak JM and Forrest LJ: Soft-tissue sarcomas. In: Small Animal Clinical Oncology, Fourth Edition. Withrow SJ and Vail DM (eds.). St Louis, MO, Sanders Elsevier, pp 425-454, 2007.

4 Vascellari M, Melchiotti E, Bozza MA and Mutinelli F: Fibrosarcomas at presumed sites of injection in dogs: characteristics and comparison with non-vaccination site fibrosarcomas and feline post-vaccinal fibrosarcomas. J Vet Med A Physiol Pathol Clin Med 50(6): 286-291, 2003. PMID: 12887620. DOI: 10.1046/j.1439-0442.2003.00544.x

5 Madej J: Pathomorphology of the sarcomas. Medycyna Weterynaryjna 74(1): 6032-2018, 2018. DOI: 10.21521/mw.6032

6 Martano M, Iussich S, Morello E and Buracco P: Canine oral fibrosarcoma: Changes in prognosis over the last 30 years? Vet J 241: 1-7, 2018. PMID: 30340654. DOI: 10.1016/j.tvj1. 2018.09.005

7 Rettig WJ, Garin-Chesa P, Healey JH, Su SL, Jaffe EA and Old LJ: Identification of endosialin, a cell surface glycoprotein of vascular endothelial cells in human cancer. Proc Natl Acad Sci U.S.A. 89(22): 10832-10836, 1992. PMID: 1438285. DOI: 10.1073/pnas.89.22.10832

8 Rouleau C, Curiel M, Weber W, Smale R, Kurtzberg L, Mascarello J, Berger C, Wallar G, Bagley R, Honma N, Hasegawa K, Ishida I, Kataoka S, Thurberg B, Mehraein K, Horten B, Miller G and Teicher B: Endosialin protein expression and therapeutic target potential in human solid tumors: sarcoma versus carcinoma. Clinical Cancer Research 14(22): 7223-7236, 2020. DOI: 10.1158/1078-0432.CCR-08-0499

9 Lax S, Hou TZ, Jenkinson E, Salmon M, MacFadyen JR, Isacke $\mathrm{CM}$, Anderson $\mathrm{G}$, Cunningham $\mathrm{AF}$ and Buckley $\mathrm{CD}$ : CD248/Endosialin is dynamically expressed on a subset of stromal cells during lymphoid tissue development, splenic remodeling and repair. FEBS Lett 581(18): 3550-3556, 2007. PMID: 17628549. DOI: 10.1016/j.febslet.2007.06.063

10 Maia M, DeVriese A, Janssens T, Moons M, Lories RJ, Tavernier J and Conway EM: CD248 facilitates tumor growth via its cytoplasmic domain. BMC Cancer 11: 162, 2011. PMID: 21549007. DOI: $10.1186 / 1471-2407-11-162$

11 Hendrick MM, Mahaffey EA, Moore FM, Vos JH and Walder EJ: Histological classification of mesenchymal tumors of skin and soft tissues of domestic animals. American Registry of Pathology, US Second Series Volume 2, Washington D.C. 1998.

12 Meuten DJ: Appendix: Diagnostic schemes and algorithms. In: Tumors in domestic animals, Fifth Edition. Wiley Blackwell, Ames, pp 942-978, 2017. DOI: 10.1002/9781119181200

13 Remmele W and Stegner HE: Recommendation for uniform definition of an immunoreactive score (IRS) for immunohistochemical estrogen receptor detection (ER-ICA) in breast cancer tissue. Pathologe 8(3): 138-40, 1987. PMID: 3303008

14 Madej JA: Rola immunohisto(cyto)chemii, antygenów oraz markerów komórkowych w diagnostyce i histogenezie nowotworów. Med Weter 75(1): 9-18, 2019. DOI: 10.21521/ mw.6129

15 Nestvold J, Wang MY, Camilio KA, Zinöcker S, Tjelle TE, Lindberg A, Haug BE, Kvalheim G, Sveinbjørnsson B and Rekdal Ø: Oncolytic peptide LTX-315 induces an immunemediated abscopal effect in a rat sarcoma model. Oncoimmunology 6(8): e1338236, 2017. PMID: 28920000. DOI: $10.1080 / 2162402 X .2017 .1338236$

16 Weiss SW and Goldblum JR: Enzinger and Weiss's soft-tissue tumors. Mosby, St. Louis, pp 6-19, 2001. 
17 Bray JP: Soft-tissue sarcoma in the dog - part 1: A current review. J Small Anim Pract 57(10): 510-519, 2016. DOI: 10.1111 jsap. 12556

18 Brown DC and Gatter KC: Monoclonal antibody Ki-67: its use in histopathology. Histopathology 17(6): 489-503, 1990. PMID: 2076881. DOI: 10.1111/j.1365-2559.1990.tb00788.x

19 Madewell BR: Cellular proliferation in tumors: A review of methods, interpretation, and clinical applications. J Vet Intern Med 15: 334-340, 2001. DOI:10.1111/j.1939-1676.2001. tb02326.x

20 Ettinger SN, Scase TJ, Oberthaler KT, Craft DM, McKnight JA, Leibman NF, Charney SC and Bergman PJ: Association of argyrophilic nucleolar organizing regions, Ki-67, and proliferating cell nuclear antigen scores with histologic grade and survival in dogs with soft tissue sarcomas: 60 cases (19962002). J Am Vet Med Assoc 228(7): 1053-1062, 2006. PMID: 16579784. DOI: $10.2460 /$ javma.228.7.1053

21 Nowak M, Madej JA and Dziegiel P: Expression of E-cadherin, beta-catenin and $\mathrm{Ki}-67$ antigen and their reciprocal correlations in fibrosarcomas of soft tissues in dogs. In Vivo 21(5): 751-756, 2007. PMID: 18019408.

22 Nowak M, Madej JA and Dzięgiel P: Intensity of COX2 expression in cells of soft-tissue fibrosacrcomas in dogs as related to grade of tumour malignancy. Bull Vet Inst Pulawy 51: n275-279, 2007.

23 Mohammed SI, Khan KN, Sellers RS, Hayek MG, DeNicola DB, Wu L, Bonney PL and Knapp DW: Expression of cyclooxygenase-1 and 2 in naturally-occurring canine cancer. Prostaglandins Leukot Essent Fatty Acids 70(5): 479-483, 2004. PMID: 15062852. DOI: 10.1016/j.plefa.2003.10.002
24 Dempke W, Rie C, Grothey A and Schmoll HJ: Cyclooxygenase2: a novel target for cancer chemotherapy? J Cancer Res Clin Oncol 127(7): 411-417, 2001. PMID: 11469677. DOI: 10.1007/ s004320000225

25 Mohammed SI, Bennett PF, Craig BA, Glickman NW, Mutsaers AJ, Snyder PW, Widmer WR, DeGortari AE, Bonney PL and Knapp DW: Effects of the cyclooxygenase inhibitor, piroxicam, on tumor response, apoptosis, and angiogenesis in a canine model of human invasive urinary bladder cancer. Cancer Res 62(2): 356-358, 2002. PMID: 11809678.

26 O'shannessy D, Dai H, Mitchell M, Huntsman S, Brantley S, Fenstermacher D and Reed D: Endosialin and associated protein expression in soft tissue sarcomas: A potential target for antiendosialin therapeutic strategies. Sarcoma 2016: 1-13, 2016. DOI: $10.1155 / 2016 / 5213628$

27 Thway K, Robertson D, Jones RL, Selfe J, Shipley J, Fisher C and Isacke CM: Endosialin expression in soft tissue sarcoma as a potential marker of undifferentiated mesenchymal cells. Br J Cancer 115(4): 473-479, 2016. PMID: 27434038. DOI: 10.1038/ bjc. 2016.214

28 Teicher BA: CD248: A therapeutic target in cancer and fibrotic diseases. Oncotarget 10(9): 993-1009, 2019. PMID: 30847027. DOI: $10.18632 /$ oncotarget.26590

Received December 21, 2020

Revised January 29, 2021

Accepted February 8, 2021 